\title{
Dissimilation by surface correspondence in Aghem velarized diphthongs*
}

\author{
Matthew Faytak \\ University of California, Berkeley
}

\section{Introduction}

Aghem, a Grassfields Bantu language spoken in Cameroon, exhibits a static co-occurrence restriction involving an intrusive velar segment present in two falling diphthongs in the language, /iya/ and /uyo/. I provide a brief overview of the structure, distribution, and provenance of these segments and offer an analysis based in Agreement by Correspondence that touches upon an unusual interaction between vowel and consonant.

I analyze the restrictions on velarity in Aghem using $\mathrm{ABC}$ with quantized segments $(\mathrm{ABC}+\mathrm{Q})$, which accomodates the apparent correspondence between the onset and a subsegmental portion of the following vowel (Inkelas \& Shih, 2013a). In a broader sense, I follow Bennett (2013)'s formulation of ABC, which is geared towards allowing analysis of patterns of dissimilation. The analysis undertaken here exhibits two unusual features: first, subphonemic content must be referenced to fully explain the observed patterns: bilabial and labiodental onsets are triggers for dissimilation of the intrusive velar only when the velar itself is rounded due to low-level coarticulation. Secondly, the correspondence described is a non-local interaction between a consonant and the most constricted sub-part of an immediately following vowel, an extremely uncommon (if not uniquely attested) pattern in the world's languages; as such, it serves as an entry point for further potential investigations.

\section{Intrusive velar overview}

Aghem is spoken in the Grassfields region in northwestern Cameroon, near the border with Nigeria, by 26,700 speakers as of 2000 (Lewis et al., 2009). It is a member of the Grassfields Bantu family, thought to be a close relation to Narrow Bantu (Watters, 2003). In the following section, I provide a brief descriptive account of the phonetic structures involved (Section 2.1) and a phonological description of the distribution of the same (Section 2.2). In an aside, I also provide an overview of Aghem's recent phonological history (Section 2.4) in an effort to elucidate the historical source of the intrusive velars.

2.1 Phonetic structure of velarized diphthongs Aghem exhibits two falling diphthongs that may be realized with a salient velar continuant intruding between the higher portion of the diphthong and the lower portion. The intrusive velars (as I refer to them here) have a characteristic acoustic profile illustrated here by means of several spectrograms. ${ }^{1}$ The intrusive velars can be characterized as velar approximants, and are plainly visible instrumentally as a sharp reduction of intensity mid-diphthong (Figure 1). This interrupted quality can be contrasted with the intensity profile of the un-velarized version of each diphthong, which is produced in particular phonotactic contexts that will be described further in Section 2.2. Although, strictly speaking, the intrusive velars should be transcribed as [u], for ease of reading I use [y] throughout to indicate them, despite the fact that they are not the voiced fricatives that a transcription of [y] would seem to indicate.

The intrusive velar occurs in both an unrounded falling diphthong / ixya/ and a rounded falling diphthong

\footnotetext{
* Thanks are owed to the poster session audience at Phonology 2013, as well as (in alphabetical order) Sam Bowman, Sharon Inkelas, Florian Lionnet, Stephanie Shih, and John Sylak-Glassman for incisive commentary. Special thanks are reserved for Larry Hyman for repeatedly fielding my queries about his store of Aghem data. The usual disclaimers apply.

1 All acoustic data is from Larry Hyman's field recordings of the language, obtained in Cameroon in the late 1970s. I must thank him again for giving me access to these recordings and permission to print spectrograms derived from them in this section.
}

(C) 2014 Matthew Faytak

Proceedings of Phonology 2013

Completed February 18, 2014 



Figure 1: Velarized and un-velarized falling diphthongs in Aghem (initials of words not shown), with the intrusive velar visible at left as a sharp decrease in intensity compared to the usual intensity profile of a falling diphthong.

/uxo/. There is no significant difference in the relative timing of the high vowel, the velar, and the low vowel portions of the rounded interrupted diphthong, with the low portion consistently realized as somewhat longer than the high portion. However, a feature of the intrusive velar in a rounded context is that it is itself rounded in this context and might better be described as $[\mathrm{w}]-$ like. ${ }^{2}$ This is presumably a low-level assimilatory effect, but it is non-trivial in the later analysis, where I argue that the phonological grammar of Aghem is sensitive at some level to the subphonemic rounding of this segment.

2.2 Synchronic phonology The intrusive velars exhibit a phonological distribution characterized in (1).

(1) a. They appear as intrusive within singleton complex vowels / ia/ and /uo/.

b. They fail to appear when the immediately preceding initial is velar.

c. They also fail to appear when the immediately preceding initial is bilabial or labiodental and the vowel is $/ \mathrm{uo} /$.

Relating to (1a), Aghem's diphthongs appear to pattern as single, one-syllable vocoids rather than as sequences of two vowels in two syllables, even in the case where an intrusive velar appears to create two $\mathrm{CV}$ syllables of shape CV.yV. The primary evidence for this particular structure is from a process of high tone spreading (HTS). In brief, it appears that a $\mathrm{VyV}$ sequence is handled as if it were a single long $\mathrm{V}$ with respect to the tonal phonology, or minimally that they are treated distinctly from other surface VCV sequences.

Hyman (1979) analyzes Aghem as having an underlying two-way tonal contrast of high (H) and low (L) at the level of the syllable. When a /H/-toned syllable immediately precedes a /L/-toned syllable, the following /L/ is realized as a high-falling contour tone $[\mathrm{HL}]$. As seen in (2), when a low-toned diphthong with an intrusive velar follows a high-toned syllable - a combination that occurs very frequently, owing to high-toned noun class prefixes and the high-toned verbal infinitive prefix $e^{-}$- - the $\mathrm{VYV}$ sequence following the high-toned syllable has a [HL] contour that is realized over the entire sequence (Hyman, 1979:14). In my own examination of Aghem, I find that the difference is more precisely one of the timing of the start of the falling contour: for a stem that has a true CVCV structure, the downward pitch excursion begins on the first vowel, whereas for a stem with $\mathrm{CV \gamma}_{\gamma} \mathrm{V}$ structure, the drop begins considerable later, typically on the longer second vowel in the $\mathrm{Vy} V$ sequence. $^{3}$

2 I transcribe this realization as $\left[\mathrm{\gamma}^{\mathrm{w}}\right]$ rather than $\left[\mathrm{u}^{\mathrm{w}}\right]$ for reasons described above, and opt not to use $[\mathrm{w}]$ for the sake of consistency in transcription of the intrusive velars.

3 For convenience, I write contours that range over intrusive velars as $V_{\gamma} \grave{V}$, $\mathrm{V}_{\gamma} V$, etc. 
(2) High Tone Spreading in Aghem

a. $\mathrm{H}-\mathrm{L} \rightarrow \mathrm{H}-\mathrm{HL}$

é-d̀a $\rightarrow$ é-dâ 'INF-be long'

é-zè $\rightarrow$ é-zê 'INF-loosen'

b. H-L.L (intervocalic C) $\rightarrow$ H-HL.L

é-bìlòn $\rightarrow$ é-bîlòn 'NC-journey'

é-dzòmò $\rightarrow$ é-dzômò 'INF-follow'

c. H-LyL (intervocalic y) $\rightarrow \mathrm{H}-\mathrm{HyL}$

kí-fûyà $\rightarrow$ kí-fíyà 'NC-plantain'

é-tsùnyò $\rightarrow$ é-tsúyò 'INF-descend'

Returning to the characteristics in (1b), the intrusive velar $/ \mathrm{y} /$ in Aghem also exhibits two co-occurrence restrictions with respect to the initial of the syllable in which / $\mathrm{y} /$ would appear (3). Both /ia/ and /uo/ lack the intrusive velar when the syllable initial is velar. A similar restriction applies for bilabial and labiodental onsets (which I refer to in aggregate as "labials"), but the intrusive velar only fails to appear when the diphthong is the rounded /uo/. Given that the intrusive velar is significantly rounded when it is present in the diphthong /uo/, it can be argued that both patterns result from a co-occurrence restriction on place: a syllable onset and an intrusive velar in its nucleus may not match in a broad articulatory sense, with velar-velar pairs and labial-rounded velar pairs both systematically failing to occur. ${ }^{4}$

(3) Co-occurrence restriction on intrusive velars

\begin{tabular}{|c|c|c|}
\hline Onset & /ìna/ & /uño/ \\
\hline Velar & $\begin{array}{l}\text {-kíá ‘headpad' (*-kífyá) } \\
\text {-ýà 'excrement' (*-Уífà) }\end{array}$ & 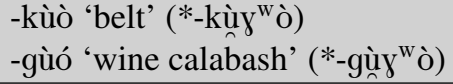 \\
\hline Labial & $\begin{array}{l}\text {-búfá ‘valley’ } \\
\text {-fị́yá ‘thing' } \\
\text {-míyà '2sg.poss.NC12' }\end{array}$ &  \\
\hline Alveolar & $\begin{array}{l}\text {-tsìyà ‘to pass' } \\
\text {-tí́yà ‘saliva' } \\
\text {-zíyá 'madness' }\end{array}$ & $\begin{array}{l}\text {-tsúf } y^{\mathrm{w}} \text { ò 'to descend' } \\
\text {-tú́ }{ }^{\mathrm{w}} \text { ó 'to shine' } \\
\text {-zúy }{ }^{\mathrm{w}} \text { 'ó 'to thatch' }\end{array}$ \\
\hline
\end{tabular}

2.3 Arguments for underlying / $/$ / There is further evidence in favor of an underlying intrusive velar in all falling diphthongs of the shape $[\mathrm{i}(\mathrm{y}) \mathrm{a}]$ and $[\mathrm{u}(\mathrm{y}) \mathrm{o}]$ in Aghem, as I have assumed thus far. The distribution seen above could well be understood in one of two ways. On the one hand, it could be thought of in terms of an active requirement for velar glide insertion, which subsequently operates across the entire lexicon except where a constraint on within-stem place co-occurrence applies. By this account, underlying forms do not contain velar glides but exhibit them in the output wherever it is optimal to do so. However, this account overgenerates velar glides in the Aghem lexicon. Imperfective ${ }^{5}$ verb forms, which appear to be the verb stem plus a suffix $-a$, do not contain intrusive velars when the stem ends in $\dot{i}$ and the imperfective thus contains the sequence /ia/ (4a). For unclear reasons, there are also a few noun stems that might be expected to show an intrusive velar that do not, namely 'termite' and 'fly' (4b). At any rate, it appears that intrusive velars are not actively generated and must be lexically specified. Instead, the account that I assume here has the velar segment present in underlying forms. This allows us to represent the difference between stems like -dzìyà 'bundle' and -dzìa 'termite' as one of underlying velarity.

\footnotetext{
4 There is another significant interaction between the syllable onset and the intrusive velar: the intrusive velar also assimilates to the syllable onset in nasality only when the onset is an alveolar nasal, e.g. /-níyá/ $\rightarrow$ [-níná] 'to lick'; /-nùyò/ $\rightarrow$ [-nùg ${ }^{\mathrm{w}}$ ò] 'to leave'. I do not discuss this further here, given the idiosyncracy of the phonotactics involved, but it is an interesting piece of evidence in favor of a particular surface correspondence relationship that holds more generally between the syllable initial and an immediately following intrusive velar.

5 This is a slight adaptation from Hyman (1979)'s term "incompletive" (78).
} 
(4) a. Derived environment effect on intrusive velar (Hyman, 1979:82)

i. sí 'to exit' $\rightarrow$ sia 'exit.IPFV' (*siya)

ii. tsí 'to spit' $\rightarrow$ tsia 'spit.IPFV' (*tsiya)

iii. jú 'to enter' $\rightarrow$ jia 'enter.IPFV' (*jiya)

b. Lexical exceptions to intrusive velar (Hyman, 1979:8)

-dzíà 'termite'; -dzìadzìa 'fly'

2.4 Recent phonological history The specific historical development of the intrusive velars in Aghem merits discussion given the (apparent) lack of peers that this phonetic structure has in the languages of the world, a conundrum which receives more discussion at the end of this paper. Aghem appears to be innovative in its immediate linguistic context in adding the intrusive velar to the falling diphthongs /ixya/ and / uxyo/. Comparative data show not only that Aghem is alone in having this velar intrusion, but it also suggests a path for development from historically low monophthongs.

Other languages in the Ring subgroup of Grassfields Bantu (Hyman, 1980), of which Aghem is a member, show low monophthongs /a/ and /o/ for all Aghem words with / ia/ and / uo/ respectively (Figure $2)$. At least two syllable codas are eliminated prior to diphthongization: $*_{-} l$ has no effect on the quality of the preceding vowel, and $*_{-} b$ has a rounding effect on the preceding vowel, effectively merging the sequence $*_{-} a b$ with whatever category develops into the rounded diphthong. Weh, the other language that shows some diphthongization (of $* a$ only), is generally included in the Western Ring subgroup to which Aghem more specifically belongs (Hyman, 1980:247-50). ${ }^{6}$

\begin{tabular}{|c|c|c|c|c|}
\hline & Aghem & Weh & Kom & Lamnso' \\
\hline$-a>-\dot{a} a$ & $-\dot{i}(\gamma) a$ & ї & -0 & $-a(a)$ \\
\hline thing & -fiya & -fæ̈ & - fo & -faa \\
\hline two & -bija & -bìว & -bo & -baa \\
\hline bridges & -liya & -lì & -10 & -laa \\
\hline seven & -siyambiya & -sỉəmbi் & -sombo & -saamba \\
\hline$-a l>-a>-\dot{i} a$ & $-\dot{i}(\gamma) a$ & -ì & -al & -ar \\
\hline valley & -bija & -bì & -bal & - \\
\hline headpad & -kia & -kì & -kal & -kar \\
\hline$*_{-a b}>-\mathrm{o}>-\mathrm{uo}$ & $-\mathrm{u}(\mathrm{\gamma}) \mathrm{O}$ & -aw & $-\mathrm{O}$ & -av \\
\hline to be strong & -tuyo & taw & -to & $-\operatorname{tav}$ \\
\hline house & -nduyo & ndaw & -ndo & -lav \\
\hline$*_{-\mathrm{O}}>-\mathrm{uo}$ & $-\mathrm{u}(\mathrm{\gamma}) \mathrm{O}$ & $-\mathrm{O},-\mathrm{U}$ & $-\mathrm{y}$ & $-\mathrm{J},-\mathrm{u}$ \\
\hline snake & -zuyo & $-\mathrm{ZO}$ & $-3 \mathrm{Y}$ & yo \\
\hline$*_{-\mathrm{ol}}>-\mathrm{uo}$ & $-\mathrm{u}(\mathrm{\gamma}) \mathrm{O}$ & $-\mathrm{O}$ & $-\mathrm{Y}$ & $\mathrm{n} / \mathrm{a}$ \\
\hline to quarrel & -zuyo & - & -yol & - \\
\hline to be tired & -buo & -bo & -bol & - \\
\hline
\end{tabular}

Figure 2: The development of falling diphthongs in Western Ring (Aghem, Weh). Data from Hyman \& Jisa (1978), a comparative Ring wordlist, and Grebe \& Grebe (1976), a separate document on Lamnso'.

As such, diphthongization and raising of $* a$ and $*_{o}$ are developments particular to the Western Ring languages, and diphthongization of $*_{o}$ appears to be restricted entirely to Aghem. Development of the intrusive velar is seen only in Aghem and does not appear to have any consonantal origin. I opt not to speculate on the motivation for this unusual innovation.

\section{Agreement by Correspondence analysis}

I argue for an analysis of intrusive velars under Agreement by Correspondence (ABC), with the addition of subsegments (Inkelas \& Shih, 2013a) and subphonemic detail (Lionnet, this volume) to enrich the

6 The source of the Weh data provided here, Hyman \& Jisa (1978), transcribes Weh [u] in words corresponding with Aghem [i(y)a]. However, upon checking field recordings of Weh provided by Hyman, the vowel transcribed as [u] has a distinctly falling quality to it; I have transcribed it here approximately as I hear it. 
representations to the point where the Aghem intrusive velars can be fully accounted for. An analysis containing all of these factors allows us to account for two unusual features of the distribution: first, it appears to be sensitive to subphonemic rounding of the intrusive velar in the rounded diphthong. Secondly, it motivates the targeting of only the most consonantal subsegment of the syllable nucleus-the intrusive velar - as the site of dissimilation, rather than the entire complex vowel; this is especially instrumental in explaining the preservation of lip-rounding on the rounded diphthong / uxyo/.

3.1 Dissimilation through surface correspondence Agreement by Correspondence (ABC) is a framework for analysis of long-distance agreement where no obvious spread occurs through intervening material (Rose \& Walker, 2004). The key innovation in ABC is the use of a constraint family generalizable as CORR-QQ, which assigns violations for segments $Q$ that are not held in surface correspondence (5). These segments $\mathrm{Q}$ are referred to as $\mathrm{C}$ (onsonants) in the original formulation of the constraint, given that $\mathrm{ABC}$ was originally proposed to account for long-distance consonant harmony. However, $\mathrm{ABC}$ has since been used in modeling interactions between segments at both long and short distances, including assimilations and dissimilations of consonants, vowels, and tones (Rhodes, 2010; Bennett, 2013; Inkelas \& Shih, 2013b). As such, I use the more general label Q, after Inkelas \& Shih (2013a), to cover the full range of segments and suprasegmentals that may be implicated in such an analysis.

(5) CORR-QQ constraint schema (Rose \& Walker (2004:491), Inkelas \& Shih (2013a)):

Let $\mathrm{S}$ be an output string of segments and let $\mathrm{Q}_{i}, \mathrm{Q}_{j}$ be segments that share a set of features $\mathbf{F}$. If $\mathrm{Q}_{i}, \mathrm{Q}_{j} \in \mathrm{S}$ then $\mathrm{Q}_{i}$ is in correspondence with $\mathrm{Q}_{j}$. Assign a violation for each $\mathrm{Q}_{i}, \mathrm{Q}_{j}$ not in correspondence.

Additional constraint families developed in Bennett (2013) are required to model the dissimilation I propose to explain the co-occurrence restrictions between the onset of a syllable and an immediately following intrusive velar. In Bennett (2013)'s analysis of dissimilation through surface correspondence, segments dissimilate or even delete in order to avoid correspondence under the CORR family of constraints, which would result in a suboptimal pattern of agreement. Suboptimality of agreement results from sufficiently highranked CC-LIMITER constraints, which penalize pairs of corresponding consonants that do not fit certain specified criteria. This class of constraints is not homogenous and includes the CC-IDENT constraints, which penalize corresponding $\mathrm{C}_{i}, \mathrm{C}_{j}$ pairs that do not agree for certain sets of features (6). ${ }^{7}$

(6) QQ-IDENT constraint schema (Bennett (2013:72), Inkelas \& Shih (2013a))

If two segments $\mathrm{Q}_{i}, \mathrm{Q}_{j}$ correspond, then they agree in a feature $[ \pm \mathrm{F}]$. Assign a violation for each corresponding $\mathrm{Q}_{i}, \mathrm{Q}_{j}$ not agreeing in $[ \pm \mathrm{F}]$.

For Aghem, I posit the CORR-QQ constraint in (7), where the similarity basis for correspondence is a constriction degree sufficiently narrow to exclude vocoids and a matching place of articulation. (The notion of a "sufficiently consonantal" will be developed in the following section.) Following Bennett (2013), I also posit the IDENT constraint in (8). Dissimilation occurs in the similarity condition for correspondence, such that the intrusive velar $/ \mathrm{y} /$ reduces its constriction degree to avoid correspondence, and a subsequent violation of constraints penalizing major class change or phonotactic constraints penalizing suboptimal sequences of vowels or consonants. The result is a "reabsorption" of the intrusive velar into the vowel, which is realized as a "plain," non-velarized diphthong.

(7) CORR-QQ[cons, $\alpha \mathrm{POA}]$ (Aghem-specific CoRR constraint)

Let $\mathrm{S}$ be an output string of segments and let $\mathrm{Q}_{i}, \mathrm{Q}_{j}$ be segments that are sufficiently consonantal and actively use the same articulators. If $\mathrm{Q}_{i}, \mathrm{Q}_{j} \in \mathrm{S}$, then $\mathrm{Q}_{i}$ is in correspondence with $\mathrm{Q}_{j}$.

(8) QQ-IDENT[cons] (Aghem-specific IDENT constraint, first try)

If $\mathrm{Q}_{i}$ and $\mathrm{Q}_{j}$ are in correspondence, then $\mathrm{Q}_{i}$ and $\mathrm{Q}_{j}$ are identical in their values for consonantality (constriction degree).

\footnotetext{
7 Other types of CC-LIMITER constraint discussed in Bennett (2013) include those penalizing correspondences between consonants in differing structural positions (CC-SROLE) and those penalizing correspondences that reach beyond certain phonological structures (CC-SYLLADJ) or morphological domains (CC-EDGE). For a full exposition of these types the reader is encouraged to consult Bennett (2013:70-104).
} 
The CORR and IDENT constraints in (7-8), as they might first be formulated, cause a significant overgeneration of dissimilation in Aghem; they would have the effect of allowing dissimilation of a coda from an onset or of an intrusive velar from a prefix, which is not attested. Dissimilation appears to operate only when one correspondent is an onset and another correspondent is an intrusive velar. Numerous CVC stems occur in Aghem with both C at the same place of articulation (9a). There are additionally no observable restrictions on combinations of noun class prefixes and noun stem initials. I have largely omitted noun classes from the discussion thus far, but the relevant labial and velar-having prefixes, /fi $/-$ 'class 11 ' and /ki/- 'class 7' (Hyman, 1979:19), freely appear before consonants of the same broad place without triggering dissimilatory phenomena $(9 \mathrm{~b})$.

(9) a. No effect of onsets on coda consonants: /-kòy/ 'mixing stick'; /-bòm/ 'hand piano' (*kò, bò)

b. No effect from stem prefix onset $\mathrm{C}$ : kí-bíná 'NC-leopard' (*kí-búá)

In short, a generalization can be made that Aghem does not show dissimilation unless the intrusive velar target is available and the scope of correspondence leading to it is within the stem. Given that the intrusive velar only developed in open syllables, and the resulting lack of syllable codas immediately following intrusive velars, this restricts the candidates for correspondence (and thus dissimilation) to the syllable initial. In order to capture this restriction, I elaborate the IDENT constraint to capture the proximity that is evidently required for correspondence to be generated (10). The colon notation is borrowed from Inkelas \& Shih (2013b) and marks off intervening material, in this case the very short vowel at the start of a velarized diphthong.

(10) CORR-Q:v:Q[cons, $\alpha$ POA] (Aghem-specific CoRR constraint)

Let $\mathrm{S}$ be an output string of segments and let $\mathrm{Q}_{i}, \mathrm{Q}_{j}$ be segments separated by one sufficiently short vocoid that are sufficiently consonantal and actively use the same articulators. If $\mathbf{Q}_{i}, \mathbf{Q}_{j} \in \mathrm{S}$, then $\mathrm{Q}_{i}$ is in correspondence with $\mathrm{Q}_{j}$.

While the similarity bases of correspondence and subsequent dissimilation are now clearer, the specific structures involved must also be incorporated into the analysis. This is particularly important given that the intrusive velar does not appear to be a standalone segment but rather one part of a complex unit segment, a velarized diphthong. As such, in Section 3.2 below, I shift my focus to developing the specific subsegmental and subphonemic representations required to fully account for the Aghem data.

3.2 Subphonemic detail and subsegmental structure in similarity On the one hand, the appearance or non-appearance of Aghem intrusive velars cannot be fully accounted for unless surface correspondence takes subphonemic factors into account in determining threshholds of similarity (Lionnet, this volume). More specifically, deletion of the intrusive velar when following a bilabial intitial and as a part of the rounded diphthong /ưyo/ appears to be due to contextual rounding of the intrusive velar and resultant similarity. Aghem does not have phonemic labiovelar segments, nor is there any compelling evidence for viewing the rounding of $/ \mathrm{y} /$ as categorical. All the same, the type of dissimilation triggered by velar onset consonants is seen to also be triggered by labial onsets when $/ \mathrm{y} /$ is rounded contextually.

Additionally, I argue that a subsegmental unit of velarized diphthongs is in fact the unit entering into correspondence with the syllable initial, given that dissimilatory changes appear to be limited to only one part of the Aghem diphthongs at issue, the intrusive velar. ABC with Quantized Segments (ABC+Q, Inkelas $\&$ Shih (2013a)) allows us to make reference to the intrusive velar as a subsegment of the complex vowels it is contained within, and to build this specific structure into the CORR constraints employed in the final analysis. I posit the subsegmental structures in Figure 3. The intrusive velar [x] is a subsegment of a larger unit diphthong in correspondence with the immediately preceding syllable initial on the basis of their relatively high degree of constriction. Following Inkelas \& Shih (2013a)'s ABC+Q framework, I break the velarized diphthong $\left[\mathrm{V}_{\gamma} \mathrm{V}\right]$ (a whole segment, $\mathrm{Q}$ ) down into three subsegments $\left(\mathrm{q}_{1-3}\right)$.

Thus, yet another version of the CORR constraint in (10) is put forward as (11), which takes into account the structure of velarized diphthongs as contour segments. 

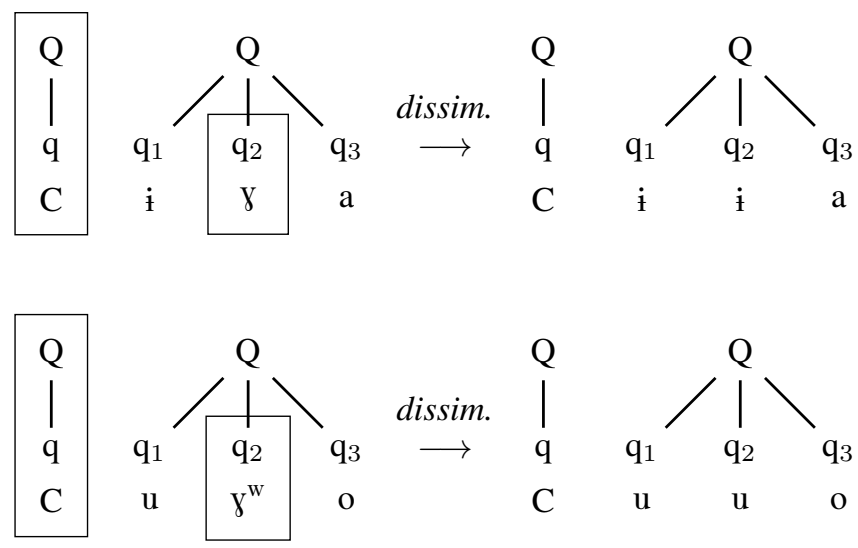

Figure 3: Velarized and de-velarized diphthongs. Left: velarized diphthongs, with possible correspondence based on [cons] indicated with boxes. Right: de-velarized diphthongs; no correspondence possible.

(11) CORR-Q:v:q $\mathrm{q}_{2}$ [cons, $\left.\alpha \mathrm{POA}\right]$ :

Let $\mathrm{S}$ be an output string of segments and let $\mathrm{Q}_{i}, \mathrm{Q}_{j}$ be segments separated by one vocoid subsegment that are sufficiently consonantal and actively use the same articulators. If $\mathrm{Q}_{i}, \mathrm{Q}_{j} \in \mathrm{S}$, then $\mathrm{Q}_{i}$ is in correspondence with $\mathrm{Q}_{j}$.

Other analyses of the distributional restrictions placed on velar glides in Aghem are tempting, but ultimately fall short of the $\mathrm{ABC}+\mathrm{Q}$ account in descriptive terms. One obvious alternative is to represent the velars as a [+PLACE]-type specification over the whole of both /uo/ and /ia/), realized vowel-medially through Aghem-specific phonetic implementation, which can then interact with initial consonants locally. The restrictions could then be summed up as a manifestation of the Obligatory Contour Principle (OCP), in which a CV sequence cannot contain identical [POA] specifications for POAs [+velar] or [+labial]. This account on its own would not capture, however, the fact that most sequences of labials and velars are in fact allowed in Aghem, for instance a bilabial stop preceding a rounded vowel. If the features that were disallowed in combination were local by virtue of being assigned to entire segments, then we would expect, for instance, an unrounding of the entirety of the diphthong /uo/ before labial and labiodental initials, which is seen not to occur in Aghem.

3.3 Constraint grammar The constraint grammar that results from the interaction of the constraints in (8) and (11), along with several LIMITER-type constraints that generate suboptimality of correspondence, create a simple version of Bennett's "essential ranking configuration for dissimilation" (105), in which CORRQQ[F], IDENT-QQ, and general phonotactic constraints outrank faithfulness constraints for the feature F in CORR-QQ[F], such that the direction of correspondence avoidance is determined by the nature of CORR itself. The general phonotactic constraints and faithfulness constraints are defined in (12).

(12) a. IDENT-[cons]: assign one violation to each candidate that alters the [cons] feature of a segment.

b. IDENT-Ons-[cons]: assign one violation to each candidate that alters the [cons] feature of a syllable onset.

c. ${ }^{*} \mathrm{CvC}$ : assign one violation to each candidate with maximally consonantal consonants flanking a vowel (sub)segment of less than full length.

The usefulness of ${ }^{*} \mathrm{CvC}$ as a constraint is predicated on the definition of a "maximally consonantal consonant," which is necessarily related to the definition of a "sufficiently consonantal consonant" used in the CORR constraint in (7). These levels of consonantality, which I do not hold to be binary (e.g. [ \pm cons]) following Padgett (2008), can be split into three constriction degrees. I define these in an ad-hoc fashion, 
with the intrusive velar and other glides occupying the middle degree, while all other $\mathrm{C}$ are at the most constricted extreme and all V are at the least constricted extreme (13). Segments of Degree 1 are "maximally consonantal"; segments of Degrees 1 and 2 are "sufficiently consonantal".

(13) Consonantality in Aghem (after Padgett (2008:1947)):

Degree 1: C other than intrusive velars, glides

Degree 2: intrusive velars, glides

Degree 3: vowels

Tableaux illustrating relevant constraint interactions are given below in (14-17). For the sake of conserving space in each tableau, I abbreviate the CORR constraint posited in the previous section as CoRR$\mathrm{Qq}_{2}$, and IDENT- as ID- throughout. For bilabial-initial candidates with unrounded vowels, there is relatively little constraint interaction to discuss, as can be seen in (14) ${ }^{8}$ The non-corresponding and faithful candidate wins due to the lack of motivation for correspondence. ${ }^{9}$ Other candidates in which the intrusive velar undergoes dissimilation in consonantality recieve a more detailed treatment below.

\begin{tabular}{|c|c|c|c|c|c|c|}
\hline & /báyá/ 'valley' & CORR-Qq 2 & $\mathrm{Qq}_{2}$-ID[cons] & $* \mathrm{CvC}$ & ID-Ons[cons] & ID[cons] \\
\hline $\mathrm{a}$. & bíyá & & 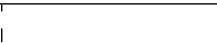 & & & \\
\hline b. & $\mathrm{b}_{i} \hat{f}_{1} \gamma_{i} \mathrm{a}$ & & $* !$ & & & \\
\hline & $\mathrm{b}_{i} \hat{\Upsilon}_{1} \mathrm{~g}_{i} \mathrm{a}$ & & & $* !$ & & $*$ \\
\hline & $\beta_{i \text { İ́ }} \gamma_{i}$ á & &  & & $* !$ & $*$ \\
\hline e. & bíáá & & & & & $*$ \\
\hline
\end{tabular}

Candidates in which the input onset consonant matches the intrusive velar for velarity and contextually determined rounding undergo dissimilation in consonantality in order to avoid correspondence, which compels (through the $\mathrm{Qq}_{2}$-IDENT[cons] constraint) the formation of undesirable $\mathrm{CvC}$ sequences. Repairs are limited to the reduction in constriction degree of the intrusive velar by other constraints: in particular, IDENT-Ons[cons] places a premium on the maintenance of onset constriction degree. For instance, when the candidate is velar-initial, the initial must satisfy the CORR constraint by entering into correspondence with the intrusive velar or by removing itself from correspondence; this leads to the latter's deletion in both the rounded and unrounded diphthongs (15-16). Alteration or deletion of the initial violates high-ranked ID-Ons[cons]; as such, candidates that do not alter the intrusive velar are harmonically bound by those that do.

\begin{tabular}{|c|c|c|c|c|c|c|}
\hline & /kíyá/ 'headpad' & CORR-Qq 2 & $\mathrm{Qq}_{2}$-ID[cons] & ${ }^{*} \mathrm{CvC}$ & ID-Ons[cons] & ID[cons] \\
\hline a. & kífyá & $* !$ & & & & \\
\hline b. & $\mathrm{k}_{i} \hat{f}_{\Upsilon} \gamma_{i} \mathrm{a} a$ & & $* !$ & & & \\
\hline & 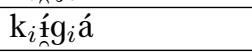 & & & $* !$ & & $*$ \\
\hline d. & $\mathrm{\gamma}_{i}$ f́d $_{i}{ }_{\mathrm{a}} \mathrm{a}$ & & & & $* !$ & * \\
\hline$\Leftrightarrow \mathrm{e}$. & kf́áá & & & & & * \\
\hline
\end{tabular}

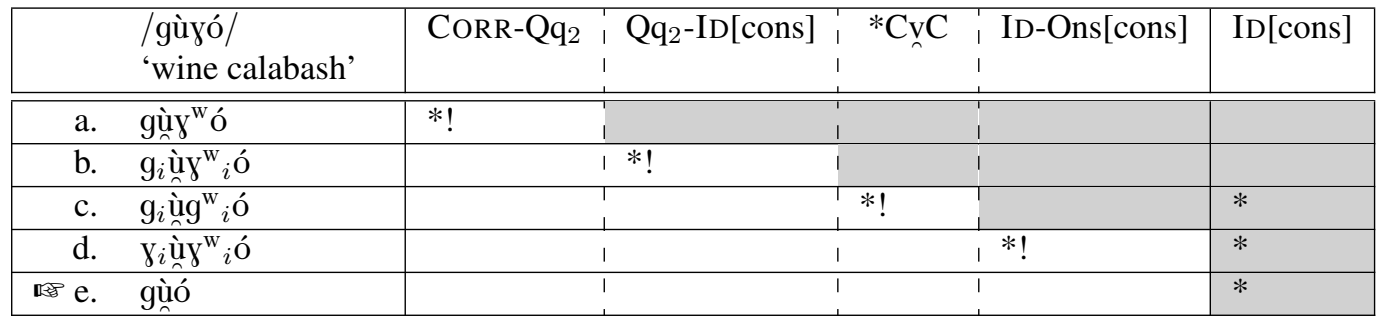

In (16), I assume low-level coarticulatory rounding applying as the result of a constraint ranked so high as to be irrelevant for present discussion; as such, I represent this rounding in all candidates considered here and in (14). This rounding is not particularly important to understanding the tableau in (16), but it is crucial

\footnotetext{
8 Note similarly that no tableaux are provided for alveolar-initial forms (e.g. [-zíyá] 'madness') for the sake of conserving space: there are no relevant constraint interactions for these forms, given the lack of correspondence required.

9 Note that in candidates (14d) and (17d), the initial $\beta$ - is intended as a glide (Degree 2) equivalent in place to /b/.
} 
if a labial initial is at issue: dissimilation of the intrusive velar is seen to occur in these cases, but only if a rounded diphthong with a contextually rounded intrusive velar follows. I have posited above that this can be thought of as broadly matching in place of articulation, with the "labials" able to enter into correspondence just as velars may.

\begin{tabular}{|c|c|c|c|c|c|c|}
\hline & /búyó/ 'to be tired' & CORR-Qq 2 & $\mathrm{Qq}_{2}$-ID[cons] & ${ }^{*} \mathrm{CvC}$ & ID-Ons[cons] & ID[cons] \\
\hline$\overline{\mathrm{a}}$. & bú́ ${ }^{\mathrm{w}}{ }^{\mathrm{w}}$ & $* !$ & & & 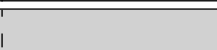 & \\
\hline b. & $\mathrm{b}_{i} \mathrm{u}_{\mathrm{N}} \gamma^{\mathrm{w}}{ }_{i} \mathrm{o}$ & & $* !$ & 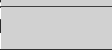 & i & \\
\hline & 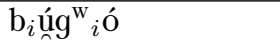 & & & $* !$ & & * \\
\hline d. & $\beta_{i}$ ú́ $_{\gamma^{\mathrm{w}}}{ }_{i}$ ó & & & & $* !$ & * \\
\hline $\mathrm{e}$. & bứó & & & & I & $*$ \\
\hline
\end{tabular}

The constraint grammar's internal ranking is summarized in the Hasse diagram in (18). Compare to the corresponding figure in Bennett (2013:105).

(18) Aghem intrusive velar dissimilation: constraint ranking

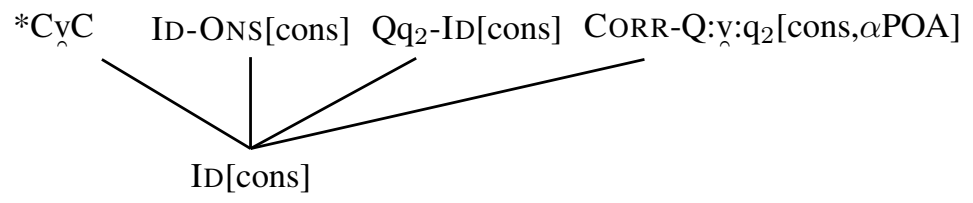

\section{Discussion and conclusions}

Aghem intrusive velars can be analyzed as occuring intervocalically in falling diphthongs when the possibility of correspondence with the immediately preceding initial consonant does not compel it to dissimilate. The constraint grammar required to model this, while entirely typical within certain formulations of Agreement by Correspondence theory, is unusual in a broader sense: very few active constraints are required, but these must be enriched with subsegmental and subphonemic information in order to fully model the phenomenon at hand.

The nature of this analysis suggests, on the one hand, that phonological representations containing a great deal of phonetic content are appropriate for Aghem, as has been suggested more generally (Flemming, 2001; Steriade, 2009). On the other hand, the complexity of the analysis may be for lack of proper comparison to another language with similar phenomena. The only other type of vowel known to me as "interrupted" is a type of glottalized vowel (e.g. V?V) often found in Mesoamerican languages (Silverman, 1997). This type of interruption is laryngeal, however, making it less likely to interact with onsets unless several series with contrastive phonation specifications are present; whether or not this actually applies in languages having vowels with interrupting glottalization is as of yet unclear.All in all, it is hoped that this research leads to further investigations into the fine structure of complex nuclei and their interactions with neighboring consonants, both as a proof-of-concept for Agreement by Correspondence analysis at short distances and as a case study for Optimality Theoretic investigations into rich phonetic representations more generally.

\section{References}

Bennett, Will (2013). Dissimilation, Consonant Harmony, and Surface Correspondence. Ph.D. thesis, Rutgers University. Flemming, Edward (2001). Scalar and categorical phenomena in a unified model of phonetics and phonology. Phonology $18: 1,7-44$.

Grebe, Karl \& Winifred Grebe (1976). A Phonology of the Nso Language. Société Internationale de Linguistique.

Hyman, Larry M. (ed.) (1979). Aghem Grammatical Structure. No. 7 in Southern California Occasional Papers in Linguistics, University of Southern California.

Hyman, Larry M. (1980). Babanki and the ring group. Les Classes Nominales dans le Bantou des Grassfields 1, $225-258$. Hyman, Larry M. \& Harriet Jisa (1978). Word list of comparative Ring. Ms.

Inkelas, Sharon \& Stephanie S. Shih (2013a). ABC+Q: Contour segments and tones in (sub)segmental Agreement by Correspondence. Handout, 21st Manchester Phonology Meeting. http://Iinguistics.berkeley.edu/ inkelas/Papers/InkelasShih-mfm2013.pdf. 
Inkelas, Sharon \& Stephanie S. Shih (2013b). Unstable surface correspondence as the source of local conspiracies. Paper presented at NELS 44 http://www.stanford.edu/ stephsus/InkelasShih_NELS_2013_ handout.pdf.

Lewis, M. Paul et al. (2009). Ethnologue: Languages of the world, vol. 9. SIL International.

Lionnet, Florian (2014). Doubly Triggered Harmony in Laal as Subphonemic Agreement by Correspondence. Supplemental Proceedings of Phonology 2013.

Padgett, J. (2008). Glides, vowels, and features. Lingua 118:12, 1937-1955.

Rhodes, Russell (2010). Vowel harmony as Agreement by Correspondence. Unpublished ms., University of California, Berkeley.

Rose, S. \& R. Walker (2004). A typology of consonant agreement as correspondence. Language 80:3, 475-531.

Silverman, Daniel (1997). Laryngeal complexity in Otomanguean vowels. Phonology 14:2, 235-261.

Steriade, Donca (2009). The Phonology of perceptibility effects: The P-Map and its consequences for constraint organization. The Nature of the Word: Studies in Honor of Paul Kiparsky, MIT Press, 151-79.

Watters, John R (2003). Grassfields Bantu. The Bantu Languages, Routledge, 225-256. 